\title{
Factors associated with past 30-day abstinence from cigarette smoking in adult established smokers who used a JUUL vaporizer for 6 months
}

\author{
Christopher Russell ${ }^{*}$ D, Farhana Haseen and Neil McKeganey
}

\begin{abstract}
Background: JUUL is the fastest growing and highest selling brand of e-cigarette/vapor products in the USA. Assessing the effect of JUUL vapor products on adult smokers' use of conventional tobacco cigarettes can help inform the potential population health impact of these products.

Methods: Participants were 15,456 US adult established current smokers aged 21 years who had purchased their first JUUL Starter Kit from a retail store or online within the past 7 days. Online surveys assessed past 30-day use of conventional cigarettes, JUUL vapor products, and other e-cigarettes/vapor products at 3 and 6 months after their first JUUL purchase. Logistic regression models examined factors associated with smokers' odds of self-reporting past 30-day abstinence from cigarette smoking at 6 months.

Results: Past 30-day point prevalence abstinence from smoking at 6 months was 31.6\% in the intent-to-treat (ITT) sample and $54.0 \%$ among those who responded at 6 months ( $n=9040 ; 58.5 \%$ of ITT). Consecutive past 30-day smoking abstinence outcomes at 3 and 6 months were reported by $20.3 \%$ of the ITT sample and $40.6 \%$ of responders to both assessments $(n=7726)$. Covariate-adjusted odds for reporting past 30-day smoking abstinence at 6 months were significantly higher among primary users of mint- or mango-flavored JUULpods (compared to primary users of Virginia tobacco-flavored JUULpods), exclusive users of JUULpods in characterizing flavors (compared to exclusive users of tobacco-flavored JUULpods), daily users of the JUUL vaporizer (compared to lessthan-daily), initial retail purchasers (compared to initial e-commerce purchasers), and those who first purchased a JUUL to help to quit smoking completely. Odds for reporting past 30-day smoking abstinence were significantly lower among those who, at study enrolment, had smoked regularly for $\geq 20$ years, smoked $\geq 10$ cigarettes per day, and smoked on all 30 of the previous 30 days.

Conclusions: Around one third of enrolled smokers and one half of smokers who responded to a 6-month followup reported being past 30-day abstinent from cigarette smoking after using a JUUL vaporizer for 6 months. More frequent use of a JUUL vaporizer and primary use of JUULpods in characterizing flavors, particularly mint and mango, appeared to be important to smokers' chances of quitting. The impact of suspending retail sales of flavored JUULpods on adult smokers' likelihood of quitting should be closely assessed.
\end{abstract}

Keywords: E-cigarettes, Vaping, Quitting, Smoking, Cigarettes, Tobacco harm reduction

\footnotetext{
* Correspondence: russell@csures.org

Centre for Substance Use Research, 4.04 West of Scotland Science Park, 2317

Maryhill Road, Glasgow G20 OSP, UK
}

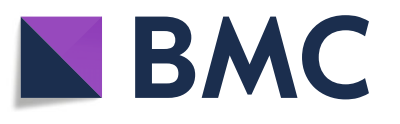

(C) The Author(s). 2019 Open Access This article is distributed under the terms of the Creative Commons Attribution 4.0 International License (http://creativecommons.org/licenses/by/4.0/), which permits unrestricted use, distribution, and reproduction in any medium, provided you give appropriate credit to the original author(s) and the source, provide a link to the Creative Commons license, and indicate if changes were made. The Creative Commons Public Domain Dedication waiver (http://creativecommons.org/publicdomain/zero/1.0/) applies to the data made available in this article, unless otherwise stated. 


\section{Background}

Smoking cigarettes and other combusted tobacco products continues to kill more people, cause more disease, and contribute more to health inequalities in highincome countries than any other preventable factor [1]. In the USA, 480,000 Americans die annually from smoking-related diseases, and around 16 million American adults are currently living and suffering with a smoking-related disease [2,3]. On average, smokers lose around 3 months of life for every year of smoking after age 35 , equating to around 10 years of life lost by lifelong smokers compared to non-smokers. Quitting tobacco smoking at the soonest opportunity is therefore the best action a person can take to reduce risks for developing chronic illness and increasing life expectancy [4, 5]. If global cigarette sales continue on trend through to 2030, around 8 million people are projected to die prematurely from a smoking-related disease each year, the majority of whom will be people who are currently smoking, not those who have yet to start [6]. Therefore, while smoking prevention efforts are critically important, encouraging and supporting more smokers to attempt to quit and providing smokers with the support and means they need to have the best chance of succeeding in their quit attempt will have a greater impact on population mortality and morbidity in the short term.

Quitting smoking is notoriously difficult, with only 3$5 \%$ of those who quit without assistance and fewer than $10 \%$ of all smokers achieving long-term abstinence, and often only after many unsuccessful quit attempts $[7,8]$. Though not approved by the US Food and Drug Administration as an aid to smoking cessation, electronic cigarettes (e-cigarettes)-hand-held devices that use battery power to heat a solution of propylene glycol, glycerol, and often flavorings and nicotine, to produce an aerosol that the user inhales-have become the most popular assisted method of quitting smoking in the USA, used in $35 \%$ of smokers' most recent quit attempts [9]. Though inconclusive, evidence from multiple population-based repeated cross-sectional [10-16] and longitudinal observational studies $[17,18]$ and from randomized controlled trials $[19,20]$ suggests that using e-cigarettes as part of a quit attempt can aid cessation. Data from multiple years of the US Current Population Survey-Tobacco Use Supplement (CPS-TUS), for example, indicate the substantial increase in e-cigarette use that occurred between 2010 and 2015 was associated with a statistically significantly $1.1 \%$ increase in the rate of smoking cessation at the population level during these years [10], with smokers who used e-cigarettes in 2014-2015 more likely to have attempted to quit smoking (65.1\% vs. $40.1 \%)$ and more likely to have succeeded in quitting smoking for at least 3 months (8.2\% vs. $4.8 \%$ ) compared to non-users of e-cigarettes. This $1.1 \%$ increase in the smoking cessation rate, equivalent to approximately 350,000 additional exsmokers, was the first significant increase in the smoking cessation rate at the population level in the USA for the past 25 years.

Other longitudinal research, however, has suggested regular e-cigarette use is associated with an increased likelihood of attempting to quit and with a substantial reduction in cigarette consumption, but not with smoking cessation at a 6-month follow-up [21] or 1year follow-up [22], and that frequent or daily ecigarette use is associated with higher odds of quitting smoking [23-25], but also with a significantly higher probability of relapse to smoking among men [26]. Additionally, though most adults who completely switch from cigarette to e-cigarettes report e-cigarettes to be a satisfying alternative to cigarettes, around five times more current smokers who tried using e-cigarettes rated them as less satisfying than cigarette and stopped using them, suggesting that, for many current smokers, ecigarettes will have to become much more satisfying if they are to replace cigarettes [27].

A common feature of these studies' assessment of the potential cessation efficacy of e-cigarettes, however, was their consideration of e-cigarette as a homogeneous category of products. The population's use and impacts of e-cigarette use, however, are likely to vary across an increasing number and heterogeneity of e-cigarette devices (e.g., size, shape, voltage), e-liquids (e.g., flavors, quality, constituents), and use behaviors (e.g., frequency of use in a month/day, puff duration, puff frequency). Obtaining data that characterize the efficacy of specific brands, makes, and models of e-cigarettes for aiding smoking cessation in real-world and trial settings is therefore key to understanding the potential contribution of each individual e-cigarette product to future population health.

The JUUL brand of vaping products has become the fastest and highest selling brand in the US e-cigarette market [28]. The JUUL vaporizer is a pod-based ecigarette that is based on a two-part system: a pre-filled, disposable e-liquid pod that clicks into a small battery. A prospective study of adult established current smokers making a first-time purchase of a JUUL vaporizer found that, 3 months later, $28.3 \%$ reported having not smoked any cigarettes for at least 30 days, with the rate of quitting found to be significantly higher among daily users of the JUUL vaporizer and among those who primarily used a JUUL vaporizer containing mint- and mangoflavored pods [29]. Longer-term data are needed, however, in order to characterize the rate at which 3-month quitters continue to report quitting across further follow-ups, the rate at which those who were still smoking at 3 months subsequently report quitting, and the rate at which 3-month quitters report having lapsed back to smoking at further follow-ups. 
In this study, we analyzed data from an ongoing prospective study of changes in smoking behavior in a large cohort of adult established current smokers in the USA up to 6 months after their first purchase of a JUUL vaporizer. We examined the rates at which new JUUL users reported having quit smoking completely or continued to use both cigarettes and the JUUL vaporizer after 3 and 6 months. We also report the rates at which those new JUUL users who had quit smoking after 3 months (i) maintained this quit or (ii) had resumed smoking at the 6-month follow-up, and the rates at which new JUUL users who reported using both cigarettes and the JUUL vaporizer at 3 months (iii) had quit smoking completely or (iv) continued to use both products at the 6-month follow-up. Additionally, we examined the extent to which demographic, smoking, and e-cigarette-related factors predicted higher and lower odds of new JUUL users reporting having quit smoking completely at the 6-month follow-up.

\section{Methods}

\section{Sample and recruitment}

Eligible individuals were US adults aged 21 years and older who had smoked at least 100 cigarettes in their lifetime, now smoke cigarettes "every day" or on "some days," and had purchased their first JUUL vaporizer Starter Kit from a US retail store or through JUUL Labs Inc.'s e-commerce store at www.juulvapor.com within the past 7 days. Individuals were eligible to participate whether or not they intended to use a JUUL as an aid to quitting smoking. Eligibility in response to each criterion was self-reported, with the exception of being aged 21 years or over, which was verified by Veratad Technologies' age verification software, AgeMatch ${ }^{S M}$ at the point of an attempted online purchase. A JUUL Starter Kit contains a JUUL vaporizer, a USB charging dock, and one pod in each of four flavors (1x Virginia tobacco, $1 \times$ mint, $1 \times$ mango, and $1 \times$ crème). Each e-liquid pod sold in a JUUL Starter Kit contains $0.7 \mathrm{~mL}$ e-liquid and is designed to contain $41 \mathrm{mg}$ of nicotine (59 $\mathrm{mg} / \mathrm{ml}$ nicotine).

Individuals were invited to participate in this study in two ways. First, JUUL Labs Inc. sent email invitations to 37,536 age-verified adults who had purchased a JUUL vaporizer Starter Kit through JUUL's e-commerce store between 4 April 2018 and 25 June 2018. The email invited individuals to participate in a 6-month online survey study about their use of combustible cigarettes, JUUL vaping products, and other brands of e-cigarettes and vaping products. Invitations were sent to the email address associated with a customer's age-verified account. An email invitation containing the web-link to the baseline survey was scheduled to be sent to each individual approximately 4 days after they completed their online purchase of a JUUL Starter Kit so as to be received by the individual within $48 \mathrm{~h}$ after the scheduled delivery of their purchased product(s).

Second, individuals who purchased a JUUL vaporizer Starter Kit in a retail store were invited to participate via $3 " \times 2.5^{\prime \prime}$ cards that were manually inserted into the packaging of 500,000 JUUL vaporizer Starter Kits, which were then distributed at random to approximately 10 , 000 licensed store retailers of JUUL vaporizer products across the USA. Starter Kits containing invitation cards were distributed across April 2018. The invitation cards contained within these Starter Kits were used to recruit new JUUL purchasers to several research studies in addition to the present study. It is not known how many of the Starter Kits containing invitation cards remain unsold on store shelves.

Printed on each invitation card insert were the invitation text, the survey web address, and a unique six-digit alphanumeric code. Individuals who purchased a JUUL vaporizer Starter Kit that contained an invitation card insert were invited to type the survey web address-survey.juul.com-into their web browser, and then, when prompted, type the six-digit code displayed on their invitation card insert. Entry of a valid code routed the individual to an Account Creation webpage, and then to the study Informed Consent Form. Each six-digit code was valid for one entry; attempts to re-use the code were blocked. Requiring the entry of a unique, one-time access code ensured that only individuals who had purchased a JUUL vaporizer Starter Kit in a retail store could proceed to the Account Creation webpage, and requiring individuals to create a user account ensured that only one survey could be completed per account.

\section{Procedure}

The first page of the survey displayed an Informed Consent Form (available upon request), which described the purpose of the survey, the names and contact details of the study investigators, information about who is eligible to take part and how survey data will be used, assurances of participant anonymity and confidentiality, and the source of funding for this study. Participants were informed they were being invited to take part in six monthly online surveys about their use of combustible cigarettes, JUUL vaporizer products, and other e-cigarettes and vapor products. Individuals who satisfied eligibility criteria and gave informed consent to participate began the survey. Participants were routed to questions that were applicable to them on the basis of a response or combination of responses to a previous question or questions. The survey instrument was designed with the assumption that all respondents to a question would be asked the next question, unless there were specific instructions routing a subgroup of respondents to a different question. 
Participants answered survey questions at their own pace. If a participant did not complete the survey, all data provided up to the point of exit from the survey was excluded from analysis.

The baseline survey took around 15 min to complete. Participants who completed the baseline survey received an automated email invitation to complete a follow-up survey $30 \pm 5$ days, $60 \pm 5$ days, $90 \pm 5$ days, and $180 \pm 5$ days after completion of the baseline survey. Two reminder emails were sent to nonrespondents within each 10-day window. Participants received a USD $\$ 30$ virtual Visa Reward Card by email for each survey they completed.

\section{Measures}

\section{Cigarette smoking in the past 30 days}

The primary outcome measure in this study was selfreported past 30-day abstinence from cigarette smoking, which was determined at each assessment by a "No" response to the question, "In the past 30 days, have you smoked a cigarette, even one or two puffs?" Participants who indicated they have smoked a cigarette in the past 30 days were asked two further questions about their frequency of smoking in the past 30 days-"Do you now smoke cigarettes..." (every day, some days, not at all), and "On how many of the past 30 days did you smoke cigarettes?" (numeric response, 1-30), and one question about their intensity of smoking in the past 30 days"On those days that you did smoke, how many cigarettes did you usually smoke each day? A pack usually has 20 cigarettes in it". Participants who did not provide answers to these four questions at the baseline assessment were excluded from the analytic sample.

\section{Cigarette smoking history}

Questions assessed the age at which participants first smoked a cigarette, first started smoking regularly, the number of months/years for which participants had been smoking cigarettes regularly, and the number of cigarettes participants had smoked in their lifetime.

\section{Use of a JUUL vaporizer and JUULpod flavors in the past 30 days}

Questions assessed the number of days in the past 30 days on which participants had used a JUUL vaporizer and the total number of JUUL vaporizer refill pods they had consumed in each of eight commercially available flavors (Virginia tobacco, mint, mango, crème, fruit, cucumber, classic tobacco, and menthol) in the past 30 days. Participants were coded as a "primary user" of a specific flavor of JUULpods when they reported having consumed more pods in that flavor than in any other flavor. For example, a participant who reported having consumed 10 mango-flavored JUULpods and 5 mint- flavored JUULpods in the past 30 days would be coded as a primary user of mango-flavored JUULpods.

Participants were coded as "past 30-day exclusive users of tobacco flavors" if they reported use of only Virginia tobacco- and/or classic tobacco-flavored JUULpods in the past 30 days. Participants were coded as "past 30-day exclusive users of characterizing flavors" if they reported use of only mint-, mango-, crème-, fruit-, cucumber-, and/or menthol-flavored JUULpods in the past 30 days. Participants were coded as "past 30-day users of both tobacco and characterizing flavors" if they reported consumption of at least one pod in Virginia tobacco or classic tobacco flavor and at least one pod in mint, mango, crème, fruit, cucumber, or menthol flavor.

\section{Use of e-cigarettes other than a JUUL vaporizer in the past 30 days}

Participants were asked if they had used any brand of ecigarette or vaping device other than a JUUL vaporizer in the 30 days prior to each assessment.

\section{Reasons for purchasing and using a JUUL vaporizer Starter Kit}

At the baseline assessment, participants were asked to identify which, if any, of a list of health, social, financial, sensory, and convenience reasons were reasons why they first decided to purchase a JUUL Starter Kit.

\section{Demographics}

Questions assessed sex, age, race/ethnicity, educational attainment, annual household income, and census region of participants' residence.

\section{Data analysis}

Rates of past 30-day abstinence from smoking at the 3month and 6-month follow-up assessments are reported for the intention-to-treat (ITT) sample $(N=15,456)$ that completed the baseline assessment. At each follow-up assessment, participants with a missing response to the question "In the past 30 days, have you smoked a cigarette, even one or two puffs?" were recoded as "smoked in the past 30 days" under the worst-case scenario assumption that these participants had returned to baseline patterns of cigarette smoking.

Rates of past 30-day abstinence from smoking at the 3-month and 6-month follow-up assessment are also reported for efficacy subsets of participants who provided smoking data at the 3 -month assessment $(n=9272$, $60.0 \%$ of the ITT sample) and the 6-month assessment ( $n=9040 ; 58.5 \%$ of the ITT sample), respectively. A rate of past 30-day abstinence from smoking at both the 3month assessment and the 6-month follow-up assessment is also reported for an efficacy subset of 7726 participants comprising those who provided smoking 
data at both the 3-month assessment and at the 6month assessment. Rates of past 30-day point prevalence abstinence from smoking observed in the ITT sample and in the efficacy subset samples were considered as lower and upper bound estimates of the rates of past 30day point prevalence abstinence from smoking at each follow-up assessment.

Factors associated with past 30-day abstinence from smoking at the 6-month assessment were examined through two logistic regression models, with each model conducted in two steps. In model 1 step 1, six demographic variables (age, sex, race/ethnicity, annual household income, education level, and US census region), four smoking history variables (age of first smoking, lifetime years of regular smoking, number of smoking days in the 30 days prior to the baseline assessment, number of cigarettes smoked per day in the 30 days prior to the baseline assessment), one e-cigarette use variable (past 30-day use of a secondary e-cigarette), and four JUUL use variables (place of first JUUL purchase, number of days of JUUL use in the past 30 days, primary JUULpod flavor used in the past 30 days, and having purchased a JUUL vaporizer to help quit smoking) were entered as predictor variables. To assess the extent to which the effect of participants' primary use of JUULpod flavors on past 30-day abstinence from smoking at the 6-month assessment was moderated by the place at which participants purchased their first JUUL Starter Kit, an interaction term for "primary JUULpod flavor use" ${ }^{\text {** }}$ "place of first purchase of a JUUL Starter Kit" was entered at step 2. Model 2 replicated model 1 with the exception that the variable "primary JUULpod flavor used in the past 30 days" was replaced by the variable "JUULpod flavors used regularly in the past 30 days" (exclusive use of JUUL tobacco flavors vs. exclusive use of JUUL characterizing flavors vs. use of flavors from both categories).

Odds ratios are reported unadjusted and adjusted for the effects of other variables in the model. Odds ratios in these regression models indicate the proportionate change in a participant's odds of self-reporting past 30-day abstinence from smoking associated with the indicator on the categorical predictor variable. Analyses were conducted using SPSS, v. 25.0. $p$ values < 0.05 were considered statistically significant.

\section{Results}

Past 30-day point prevalence abstinence from cigarette smoking

ITT sample

In the ITT sample $(N=15,456)$, past 30 -day point prevalence abstinence from smoking increased from $28.3 \%$ at the 3-month assessment to $31.6 \%$ at the 6-month assessment (Fig. 1). Approximately 20.3\% of the ITT sample reported past 30-day smoking abstinence at both the 3month assessment and the 6-month assessment (i.e., continuing quitters) (Fig. 2). In contrast, $60.4 \%$ of the ITT sample did not report past 30-day smoking abstinence at either the 3-month assessment or the 6-month assessments (i.e., continuing smokers). The rate at which participants quit smoking between the third and sixth months $(11.3 \%)$ was approximately 1.4 times higher than

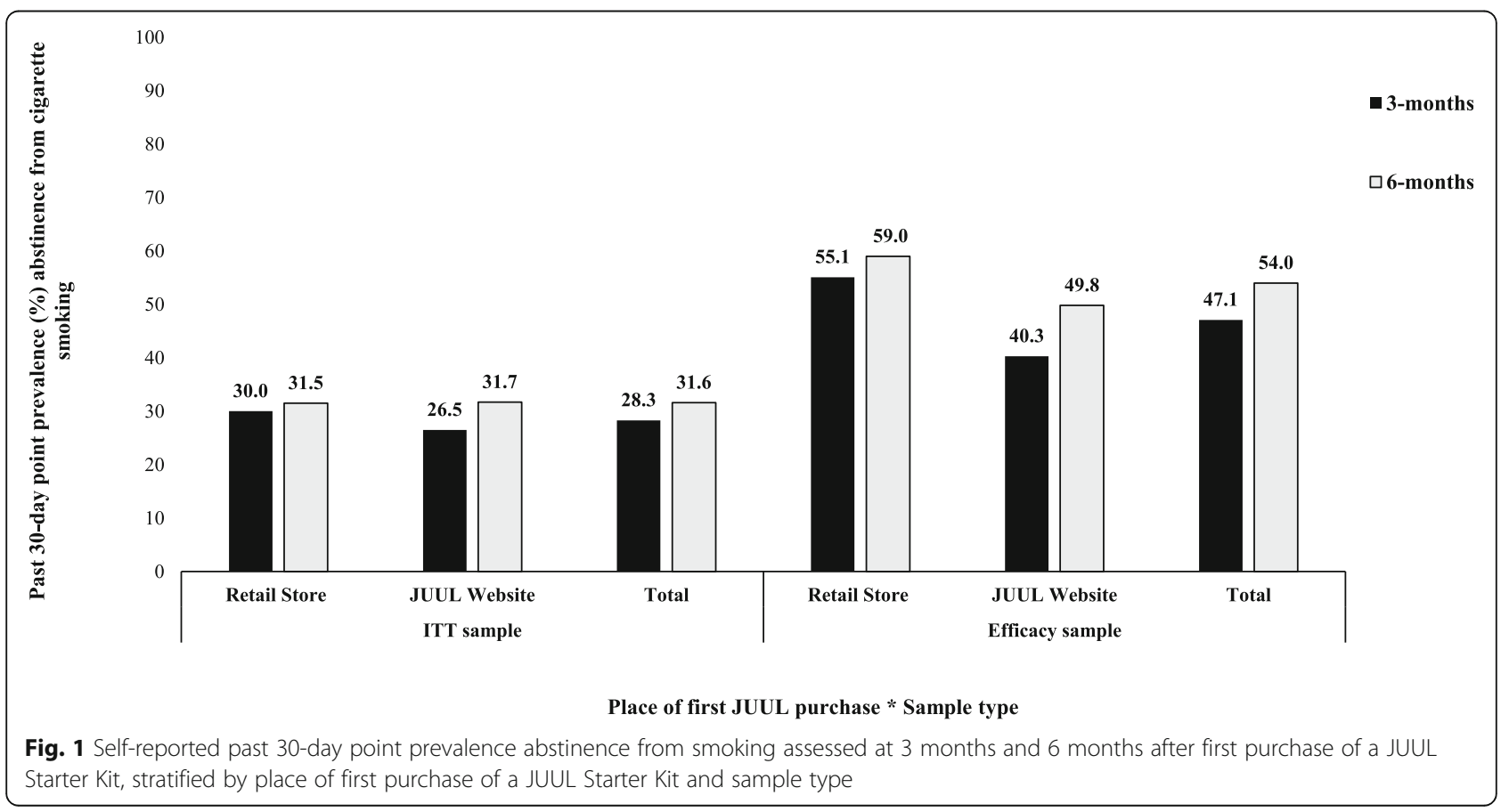




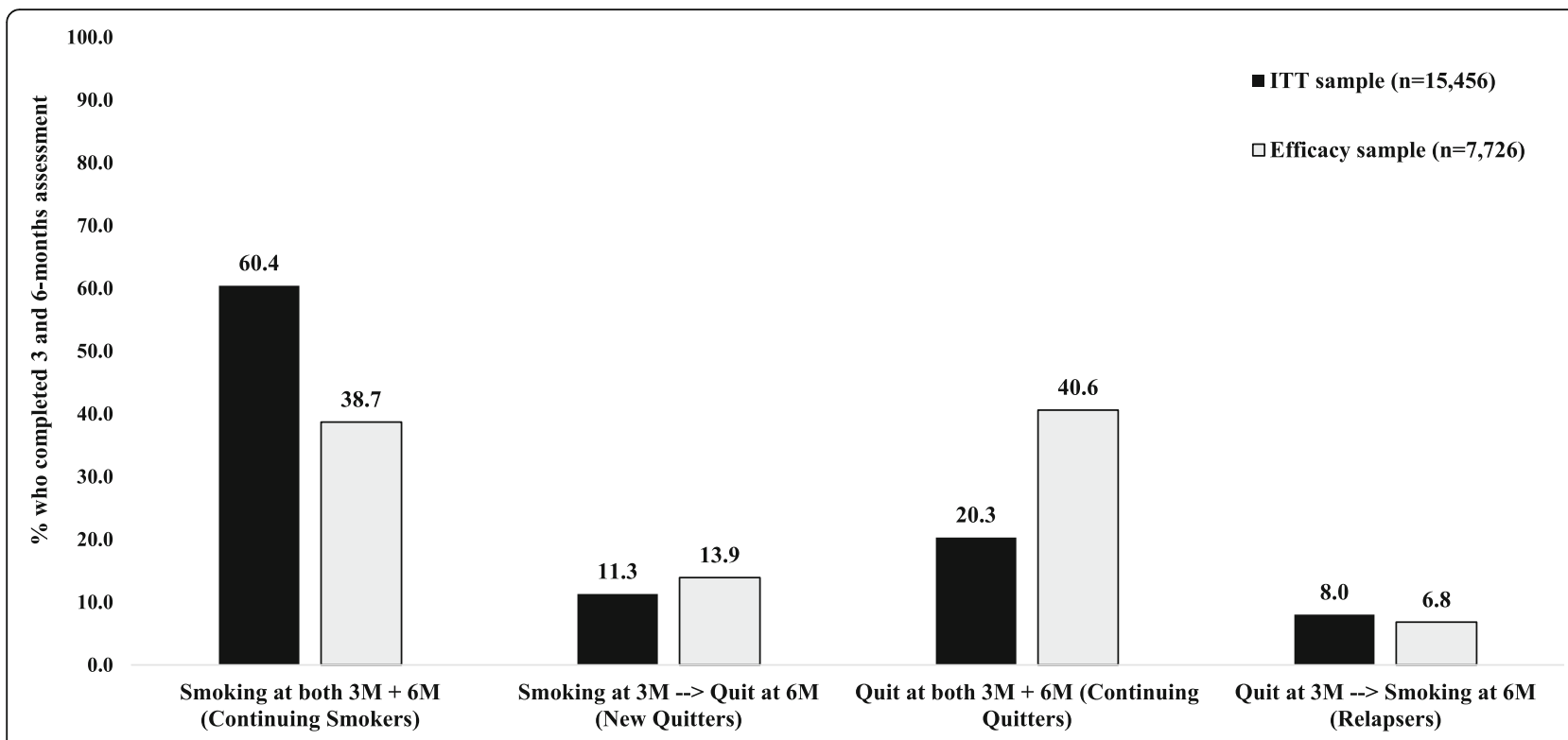

Fig. 2 Transitions in cigarette smoking status between the 3-month assessment and the 6-month assessment among new users of a JUUL vaporizer who completed both assessments

the rate at which participants lapsed back to smoking between the third and sixth (8.0\%).

\section{Efficacy subset samples}

When the analysis was restricted to only participants who completed the 3-month assessment $(n=9272)$, self-reported past 30-day point prevalence abstinence from smoking was $47.1 \%$, with the abstinence rate higher among initial retail purchasers $(55.1 \% ; n=2346$ / 4260) than among initial online purchasers (40.3\%; $n=$ $2021 / 5012$ ). When the analysis was restricted to only those who completed the 6-month assessment $(n=$ 9040 ), past 30-day point prevalence abstinence from smoking was $54.0 \%(4886 / 9040)$, with the abstinence rate again higher among initial retail purchasers $(59.0 \% ; n=2467 / 4180)$ than among initial online purchasers $(49.8 \% ; n=2419 / 4860)$.

Last, when the analysis was restricted to only participants who completed both the 3-month assessment and the 6-month assessment $(n=7726)$, past 30 -day point prevalence abstinence from smoking at both the 3month assessment and the 6-month assessment was $40.6 \%$. In contrast, $38.7 \%$ did not report past 30-day smoking abstinence at either the 3-month assessment or the 6-month assessments (i.e., continuing smokers). The rate at which participants became abstinent at the 6month assessment having been smoking at the 3-month assessment (i.e., quit smoking between the third and sixth months, $13.9 \%$ ) was approximately 2.0 times higher than the rate at which participants who were abstinent from smoking at the 3-month assessment returned to smoking at the 6-month assessment (i.e., lapsed to smoking between the third and sixth months, 6.8\%).

\section{Factors associated with past 30-day smoking abstinence at 6 months \\ Model 1}

Demographic, cigarette smoking, and e-cigarette use characteristics of new purchasers of a JUUL Starter Kit who completed the 6-month follow-up assessment $(n=$ 9040) are summarized in Table 1 , stratified by smoking abstinence status at the 6-month assessment. Adjusting for the effects of all other variables in the model, participants' odds of reporting past 30-day abstinence from smoking at the 6-month assessments significantly varied by five JUUL-related variables-(i) primary JUULpod flavor used in the 30 days prior to the 6-month assessment, (ii) number of days of use of a JUUL vaporizer in the 30 days prior to the 6-month assessment, (iii) place of first purchase of a JUUL Starter Kit, (iv) whether or not participants first purchased a JUUL vaporizer to help them quit smoking cigarettes, and (v) past 30-day use of any other e-cigarette other than JUUL vaporizer; three smoking-related variables-(i) number of smoking days in the 30 days prior to the baseline assessment, (ii) number of cigarettes smoked per smoking day at the baseline assessment, and (iii) number of lifetime years of regular smoking; and two demographic variables-(i) education level and (ii) census region (Table 2).

JUUL-related factors Mint and mango were the most common primary JUULpod flavors used in the past 30 days at 6 months. Past 30-day primary users of mint- 
Table 1 Characteristics of participants who completed the 6-month follow-up assessment ( $n=9040 ; 58.5 \%$ of ITT sample), by cigarette smoking status at the 6-month assessment

\begin{tabular}{|c|c|c|c|}
\hline \multirow[t]{2}{*}{ Variable } & \multicolumn{3}{|c|}{ Cigarette smoking status at 6-month assessment } \\
\hline & $\begin{array}{l}\text { Smoked in } \\
\text { the past } 30 \text { days } \\
(n=4154) \\
N \%\end{array}$ & $\begin{array}{l}\text { No smoking in } \\
\text { the past } 30 \text { days } \\
(n=4886) \\
N \%\end{array}$ & $\begin{array}{l}\text { Total } \\
(n=9040) \\
N \%\end{array}$ \\
\hline \multicolumn{4}{|l|}{ Demographic variables } \\
\hline \multicolumn{4}{|l|}{ Sex } \\
\hline Male & $2287(55.1)$ & $2872(58.8)$ & $5159(57.1)$ \\
\hline Female & $1798(43.3)$ & $1954(40.0)$ & $3752(41.5)$ \\
\hline Transgender & $25(0.6)$ & $28(0.6)$ & $53(0.6)$ \\
\hline Missing & $44(1.1)$ & $32(0.7)$ & $76(0.8)$ \\
\hline \multicolumn{4}{|l|}{ Age } \\
\hline $21-24$ & $1145(27.6)$ & $1846(37.8)$ & $2991(33.1)$ \\
\hline $25-34$ & $1444(34.8)$ & $1623(33.2)$ & $3067(33.9)$ \\
\hline $35-44$ & $833(20.1)$ & $746(15.3)$ & $1579(17.5)$ \\
\hline $45-54$ & $443(10.7)$ & $381(7.8)$ & $824(9.1)$ \\
\hline $55-64$ & $227(5.5)$ & $261(5.3)$ & $488(5.4)$ \\
\hline$\geq 65$ & $62(1.5)$ & $29(0.6)$ & $91(1.0)$ \\
\hline \multicolumn{4}{|l|}{ Race/ethnicity } \\
\hline Non-Hispanic, White & $2884(69.4)$ & 3255 (66.6) & $6139(67.9)$ \\
\hline Non-Hispanic, Black & $85(2.0)$ & $120(2.5)$ & $205(2.3)$ \\
\hline Non-Hispanic, Others ${ }^{\S}$ & $528(12.7)$ & $597(12.2)$ & $1125(12.4)$ \\
\hline Hispanic $^{\dagger}$ & $332(8.0)$ & $480(9.8)$ & $812(9.0)$ \\
\hline Missing & $325(7.8)$ & $434(8.9)$ & $759(8.4)$ \\
\hline \multicolumn{4}{|l|}{ Education } \\
\hline Not HS graduate & $111(2.7)$ & $122(2.5)$ & $233(2.6)$ \\
\hline GED & $151(3.6)$ & $204(4.2)$ & 355 (3.9) \\
\hline HS graduate & $625(15.0)$ & $913(18.7)$ & $1538(17.0)$ \\
\hline Some college or associate's degree & $1618(39.0)$ & 1789 (36.6) & $3407(37.7)$ \\
\hline Bachelor's degree or higher & $1466(35.3)$ & $1579(32.3)$ & $3045(33.7)$ \\
\hline Missing & $183(4.4)$ & $279(5.7)$ & $462(5.1)$ \\
\hline \multicolumn{4}{|l|}{ Household income } \\
\hline$<\$ 25,000$ & $831(20.0)$ & $1007(20.6)$ & $1838(20.3)$ \\
\hline$\$ 25,000$ to $\$ 74,999$ & $1692(40.7)$ & $2027(41.5)$ & $3719(41.1)$ \\
\hline$\geq \$ 75,000$ & $1137(27.4)$ & $1285(26.3)$ & $2422(26.8)$ \\
\hline Missing & $494(11.9)$ & $567(11.6)$ & $1061(11.7)$ \\
\hline \multicolumn{4}{|l|}{ US census region } \\
\hline Northeast & $957(23.0)$ & $1016(20.8)$ & $1973(21.8)$ \\
\hline South & $1502(36.2)$ & $1812(37.1)$ & $3314(36.7)$ \\
\hline Midwest & $1008(24.3)$ & $1116(22.8)$ & $2124(23.5)$ \\
\hline West & $647(15.6)$ & $913(18.7)$ & $1560(17.3)$ \\
\hline Missing & $40(1.0)$ & $29(0.6)$ & $69(0.8)$ \\
\hline \multicolumn{4}{|l|}{ Smoking and e-cigarette variables } \\
\hline \multicolumn{4}{|l|}{ Age of first smoking } \\
\hline$\leq 11$ years & $144(3.5)$ & $155(3.2)$ & $299(3.3)$ \\
\hline
\end{tabular}


Table 1 Characteristics of participants who completed the 6-month follow-up assessment ( $n=9040 ; 58.5 \%$ of ITT sample), by cigarette smoking status at the 6-month assessment (Continued)

\begin{tabular}{|c|c|c|c|}
\hline \multirow[t]{2}{*}{ Variable } & \multicolumn{3}{|c|}{ Cigarette smoking status at 6-month assessment } \\
\hline & $\begin{array}{l}\text { Smoked in } \\
\text { the past } 30 \text { days } \\
(n=4154) \\
N \%\end{array}$ & $\begin{array}{l}\text { No smoking in } \\
\text { the past } 30 \text { days } \\
(n=4886) \\
N \%\end{array}$ & $\begin{array}{l}\text { Total } \\
(n=9040) \\
N \%\end{array}$ \\
\hline 12 to 14 years & $1025(24.7)$ & $888(18.2)$ & $1913(21.2)$ \\
\hline 15 to 17 years & $1613(38.8)$ & $1773(36.3)$ & $3386(37.5)$ \\
\hline 18 to 24 years & $1284(30.9)$ & $1958(40.1)$ & $3242(35.9)$ \\
\hline$\geq 25$ years & $77(1.9)$ & $99(2.0)$ & $176(1.9)$ \\
\hline Missing & $11(0.3)$ & $13(0.3)$ & $24(0.3)$ \\
\hline \multicolumn{4}{|l|}{ Lifetime years of smoking } \\
\hline$\leq 1$ year & $272(6.5)$ & $556(11.4)$ & $828(9.2)$ \\
\hline $1-5$ years & $980(23.6)$ & $1600(32.7)$ & $2580(28.5)$ \\
\hline $6-10$ years & $898(21.6)$ & $1000(20.5)$ & $1898(21.0)$ \\
\hline $11-20$ years & 1065 (25.6) & $923(18.9)$ & $1988(22.0)$ \\
\hline$\geq 20$ years & $860(20.7)$ & $692(14.2)$ & $1552(17.2)$ \\
\hline Missing & $79(1.9)$ & $115(2.4)$ & $194(2.1)$ \\
\hline \multicolumn{4}{|c|}{ Number of smoking days in 30 days prior to baseline } \\
\hline $1-9$ days & $412(9.9)$ & $847(17.3)$ & $1259(13.9)$ \\
\hline 10-19 days & $380(9.1)$ & $754(15.4)$ & $1134(12.5)$ \\
\hline 20-29 days & $864(20.8)$ & $1213(24.8)$ & $2077(23.0)$ \\
\hline 30 days & $2498(60.1)$ & $2072(42.4)$ & $4570(50.6)$ \\
\hline \multicolumn{4}{|c|}{ Cigarettes smoked per day at baseline } \\
\hline 1-9 cigarettes per day & $1858(44.7)$ & 2907 (59.5) & $4765(52.7)$ \\
\hline 10-19 cigarettes per day & $1368(32.9)$ & $1284(26.3)$ & $2652(29.3)$ \\
\hline$\geq 20$ cigarettes per day & $928(22.3)$ & $695(14.2)$ & $1623(18.0)$ \\
\hline \multicolumn{4}{|c|}{ Days of JUUL vaporizer use in past 30 days at 6 months } \\
\hline 1-9 days & $469(11.3)$ & $321(6.6)$ & $790(8.7)$ \\
\hline 10-19 days & $636(15.3)$ & $431(8.8)$ & $1067(11.8)$ \\
\hline 20-29 days & $748(18.0)$ & $677(13.9)$ & $1425(15.8)$ \\
\hline 30 days & $1960(47.2)$ & $2994(61.3)$ & $4954(54.8)$ \\
\hline Missing & $341(8.2)$ & $463(9.5)$ & $804(8.9)$ \\
\hline \multicolumn{4}{|c|}{ Current use of an e-cigarette other than JUUL vaporizer } \\
\hline Yes & $553(13.3)$ & $483(9.9)$ & $1036(11.5)$ \\
\hline No & $3596(86.6)$ & $4396(90.0)$ & $7992(88.4)$ \\
\hline Missing & $5(0.1)$ & $7(0.1)$ & $12(0.1)$ \\
\hline \multicolumn{4}{|c|}{ Place of first JUUL vaporizer purchase } \\
\hline Retail store & $1713(41.2)$ & $2467(50.5)$ & $4180(46.2)$ \\
\hline JUUL website & $2441(58.8)$ & $2419(49.5)$ & $4860(53.8)$ \\
\hline \multicolumn{4}{|c|}{ Bought JUUL vaporizer SK "to help me quit smoking" } \\
\hline Yes & $3435(82.7)$ & $4103(84.0)$ & $7538(83.4)$ \\
\hline No & $719(17.3)$ & $783(16.0)$ & $1502(16.6)$ \\
\hline \multicolumn{4}{|c|}{ Primary JUULpod flavor used in past 30 days (at 6 months) } \\
\hline Virginia tobacco & $477(11.5)$ & $423(8.7)$ & $900(10.0)$ \\
\hline Mint & $820(19.7)$ & 1204 (24.6) & $2024(22.4)$ \\
\hline
\end{tabular}


Table 1 Characteristics of participants who completed the 6-month follow-up assessment ( $n=9040 ; 58.5 \%$ of ITT sample), by cigarette smoking status at the 6-month assessment (Continued)

\begin{tabular}{|c|c|c|c|}
\hline \multirow[t]{2}{*}{ Variable } & \multicolumn{3}{|c|}{ Cigarette smoking status at 6-month assessment } \\
\hline & $\begin{array}{l}\text { Smoked in } \\
\text { the past } 30 \text { days } \\
(n=4154) \\
N \%\end{array}$ & $\begin{array}{l}\text { No smoking in } \\
\text { the past } 30 \text { days } \\
(n=4886) \\
N \%\end{array}$ & $\begin{array}{l}\text { Total } \\
(n=9040) \\
N \%\end{array}$ \\
\hline Mango & $938(22.6)$ & $1334(27.3)$ & $2272(25.1)$ \\
\hline Crème & $218(5.2)$ & $180(3.7)$ & $398(4.4)$ \\
\hline Fruit & $134(3.2)$ & $127(2.6)$ & $261(2.9)$ \\
\hline Cucumber & $173(4.2)$ & $169(3.5)$ & $342(3.8)$ \\
\hline Classic tobacco & $116(2.8)$ & $54(1.1)$ & $170(1.9)$ \\
\hline Menthol & $194(4.7)$ & $170(3.5)$ & $364(4.0)$ \\
\hline Equal use of $2+$ flavors, no primary & $747(18.0)$ & $766(15.7)$ & $1513(16.7)$ \\
\hline Missing & $337(8.1)$ & $459(9.4)$ & $796(8.8)$ \\
\hline \multicolumn{4}{|l|}{ JUULpod flavors used in past 30 days (at 6 months) } \\
\hline Only used JUUL vaporizer tobacco flavors* & $443(10.7)$ & $335(6.9)$ & 778 (8.6) \\
\hline Only used JUUL vaporizer characterizing flavors^ & $2741(66.0)$ & $3531(72.3)$ & $6272(69.4)$ \\
\hline Used both tobacco and characterizing flavors & $637(15.3)$ & $568(11.6)$ & $1205(13.3)$ \\
\hline Missing & $333(8.0)$ & $452(9.3)$ & 785 (8.7) \\
\hline
\end{tabular}

Abbreviations: SK JUUL Starter Kit (JUUL vaporizer plus four JUULpods), HS high school, GED General Educational Development, PI Pacific Islander

${ }^{\S}$ Includes Asian Indian, Chinese, Filipino, Japanese, Korean, Vietnamese, Guamanian, Chamorro, Samoan, and multiple races

"Includes Mexican, Cuban, Puerto Rican, and "other Hispanic" ethnicity

*JUUL vaporizer tobacco flavors include "Virginia tobacco" and "classic tobacco"

^JUUL vaporizer characterizing flavors include "mint," "mango," "crème," "fruit," "cucumber," and "menthol"

and mango-flavored JUULpods together accounted for $51.9 \%$ of all participants who had not smoked a cigarette in the 30 days prior to the 6-month assessment, and $47.5 \%$ of all participants who completed the 6-month assessment. Compared to those who primarily used Virginia tobacco-flavored JUULpods in the 30 days prior to the 6-month assessment, those who primarily used mint- $(\mathrm{aOR}=1.45 ; 1.20,1.76)$ or mango-flavored JUULpods $(\mathrm{aOR}=1.39 ; 1.15,1.67)$ were $45 \%$ and $39 \%$ more likely, respectively, to have not smoked a cigarette in the 30 days prior to the 6-month assessment. Compared to those who primarily used Virginia tobacco-flavored JUULpods, primary users of crème-, fruit-, cucumber-, classic tobacco-, or menthol-flavored JUULpods and those who did not have a primary JUULpod flavor in the 30 days prior to the 6-month assessment had statistically equivalent odds for reporting past 30-day smoking abstinence at the 6-month assessment.

The interaction term entered at step 2 was not significant, indicating the association between primary JUULpod flavor used in the 30 days prior to the 6-month assessment and past 30-day smoking abstinence at the 6-month assessment was not moderated by the place at which participants purchased their first JUUL Starter Kit. Rates of past 30-day smoking abstinence at the 6month assessment stratified by past 30-day primary use of JUULpods in eight flavors and place of first purchase of a JUUL Starter Kit, unadjusted for the effects of other variables, summarized in Fig. 3, show that, with the exception of Crème, higher rates of past 30-day smoking abstinence at the 6-month assessment were reported by initial retail purchasers than for all JUULpod flavors.

Compared to those who used a JUUL vaporizer on all 30 of the 30 days prior to the 6 -month assessment, those who used a JUUL vaporizer on $20-29$ (aOR = $0.45 ; 0.39,0.52), 10-19(\mathrm{aOR}=0.39 ; 0.33,0.46)$, and $1-$ $9(\mathrm{aOR}=0.38 ; 0.31,0.45)$ of the past 30 days were 2.22 times, 2.56 times, and 2.63 times less likely, respectively, to have not smoked a cigarette in the 30 days prior to the 6-month assessment. Compared to those who indicated they did not purchase their first JUUL Starter Kit "to help to quit smoking cigarettes completely," those who reported having purchased their first JUUL Starter Kit "to help to quit smoking cigarettes completely" were $46 \%$ more likely to have abstained from smoking in the 30 days prior to the 6 month assessment $(\mathrm{aOR}=1.46 ; 1.26,1.68)$.

Compared to those who purchased their first JUUL Starter Kit at JUUL's e-commerce store, those who purchased their first JUUL Starter Kit in a retail store were $22 \%$ more likely to have abstained from smoking in the 30 days prior to the 6 -month assessment $(\mathrm{aOR}=1.22$; $1.08,1.37)$. Last, compared to those who had not used any e-cigarette other than a JUUL vaporizer in the 30 days prior to the 6-month assessment, those who reported past 30-day use of a secondary e-cigarette were 
Table 2 Factors associated with smokers' likelihood of reporting past 30-day abstinence from cigarette smoking at the 6-month assessment

\begin{tabular}{|c|c|c|c|c|c|c|}
\hline & & \multirow[t]{2}{*}{ Unadjusted } & \multicolumn{2}{|l|}{ Model 1 adjusted } & \multicolumn{2}{|l|}{ Model 2 adjusted } \\
\hline & & & Step 1 & Step 2 & Step 1 & Step 2 \\
\hline Predictor variable & $\%$ P30A & Unadjusted OR (95\% Cl) & $\begin{array}{l}\text { aOR } \\
(95 \% \mathrm{Cl})\end{array}$ & $\begin{array}{l}\text { aOR } \\
(95 \% \mathrm{Cl})\end{array}$ & $\begin{array}{l}\text { aOR } \\
(95 \% \mathrm{Cl})\end{array}$ & $\begin{array}{l}\mathrm{aOR} \\
(95 \% \mathrm{Cl})\end{array}$ \\
\hline \multicolumn{7}{|l|}{$\overline{\text { Sex }}$} \\
\hline Male & 55.7 & Ref. & Ref. & Ref. & Ref. & Ref. \\
\hline Female & 52.1 & $0.87(0.80-0.94)^{* *}$ & $0.96(0.86-1.07)$ & $0.96(0.86-1.08)$ & $0.95(0.85-1.06)$ & $0.95(0.85-1.06)$ \\
\hline Transgender & 52.8 & $0.89(0.52-1.53)$ & $0.82(0.42-1.59)$ & $0.82(0.42-1.59)$ & $0.87(0.45-1.67)$ & $0.87(0.45-1.67)$ \\
\hline \multicolumn{7}{|l|}{ Age } \\
\hline $21-24$ & 61.7 & Ref. & Ref. & Ref. & Ref. & Ref. \\
\hline $25-34$ & 52.9 & $0.70(0.63-0.77)^{* * *}$ & $0.96(0.82-1.12)$ & $0.96(0.82-1.12)$ & $0.96(0.82-1.13)$ & $0.96(0.82-1.13)$ \\
\hline $35-44$ & 47.2 & $0.56(0.49-0.63)^{* * *}$ & $1.00(0.79-1.25)$ & $1.00(0.80-1.25)$ & $1.00(0.80-1.25)$ & $1.00(0.80-1.25)$ \\
\hline $45-54$ & 46.2 & $0.53(0.46-0.62)^{* * *}$ & $1.09(0.82-1.46)$ & $1.10(0.83-1.47)$ & $1.10(0.83-1.46)$ & $1.10(0.82-1.46)$ \\
\hline $55-64$ & 53.5 & $0.71(0.59-0.87)^{* *}$ & $0.9(0.62-1.3)$ & $0.91(0.63-1.32)$ & $0.91(0.63-1.31)$ & $0.91(0.63-1.31)$ \\
\hline$\geq 65$ & 31.9 & $0.29(0.19-0.45)^{* * *}$ & $0.72(0.39-1.36)$ & $0.72(0.38-1.36)$ & $0.72(0.38-1.35)$ & $0.72(0.38-1.34)$ \\
\hline \multicolumn{7}{|l|}{ Race/ethnicity } \\
\hline Non-Hispanic, White alone & 53.0 & Ref. & Ref. & Ref. & Ref. & Ref. \\
\hline Non-Hispanic, Black alone & 58.5 & $1.25(0.94-1.66)$ & $1.38(0.97-1.95)$ & $1.38(0.97-1.96)$ & $1.35(0.96-1.92)$ & $1.36(0.96-1.92)$ \\
\hline Non-Hispanic, Others ${ }^{\S}$ & 53.1 & $1.00(0.88-1.14)$ & $0.95(0.81-1.11)$ & $0.95(0.81-1.11)$ & $0.96(0.82-1.12)$ & $0.96(0.82-1.12)$ \\
\hline Hispanic $^{\dagger}$ & 59.1 & $1.28(1.10-1.49)^{* *}$ & $1.08(0.90-1.29)$ & $1.07(0.90-1.29)$ & $1.07(0.89-1.28)$ & $1.06(0.89-1.28)$ \\
\hline \multicolumn{7}{|l|}{ Education } \\
\hline Not HS graduate & 52.4 & Ref. & Ref. & Ref. & Ref. & Ref. \\
\hline GED & 57.5 & $1.23(0.88-1.71)$ & $1.55(1.03-2.34)^{*}$ & $1.56(1.03-2.35)^{*}$ & $1.58(1.05-2.37)^{*}$ & $1.58(1.05-2.38)^{*}$ \\
\hline HS graduate & 59.4 & $1.33(1.01-1.75)^{*}$ & $1.09(0.78-1.53)$ & $1.10(0.79-1.54)$ & $1.10(0.79-1.54)$ & $1.10(0.79-1.54)$ \\
\hline Some college or associate's degree & 52.5 & $1.01(0.77-1.31)$ & $0.96(0.70-1.33)$ & $0.97(0.70-1.33)$ & $0.96(0.70-1.33)$ & $0.97(0.70-1.33)$ \\
\hline Bachelor's degree or higher & 51.9 & $0.98(0.75-1.28)$ & $0.90(0.65-1.25)$ & $0.90(0.65-1.26)$ & $0.92(0.66-1.27)$ & $0.92(0.66-1.27)$ \\
\hline \multicolumn{7}{|l|}{ Household income } \\
\hline$<\$ 25,000$ & 54.8 & Ref. & Ref. & Ref. & Ref. & Ref. \\
\hline$\$ 25,000$ to $\$ 74,999$ & 54.5 & $0.99(0.88-1.11)$ & $1.07(0.93-1.23)$ & $1.07(0.93-1.23)$ & $1.08(0.94-1.24)$ & $1.08(0.94-1.24)$ \\
\hline$\geq \$ 75,000$ & 53.1 & $0.93(0.83-1.05)$ & $1.10(0.94-1.29)$ & $1.10(0.94-1.29)$ & $1.12(0.95-1.30)$ & $1.12(0.95-1.31)$ \\
\hline \multicolumn{7}{|l|}{ US census region } \\
\hline Northeast & 51.5 & $0.75(0.66-0.86)^{* * *}$ & $0.84(0.71-0.99)^{*}$ & $0.83(0.70-0.99)^{*}$ & $0.84(0.71-1.00)^{*}$ & $0.84(0.71-1.00)^{*}$ \\
\hline South & 54.7 & $0.85(0.76-0.97)^{*}$ & $0.97(0.83-1.13)$ & $0.96(0.83-1.13)$ & $0.97(0.83-1.13)$ & $0.97(0.83-1.13)$ \\
\hline Midwest & 52.5 & $0.78(0.69-0.90)^{* * *}$ & $0.84(0.71-0.99)^{*}$ & $0.84(0.71-0.99)^{*}$ & $0.85(0.72-1.00)$ & $0.85(0.72-1.00)$ \\
\hline West & 58.5 & Ref. & Ref. & Ref. & Ref. & Ref. \\
\hline \multicolumn{7}{|l|}{ Age of first smoking } \\
\hline$\leq 11$ years & 51.8 & Ref. & Ref. & Ref. & Ref. & Ref. \\
\hline 12 to 14 years & 46.4 & $0.80(0.63-1.03)$ & $0.74(0.54-1.00)$ & $0.73(0.54-1.00)^{*}$ & $0.74(0.55-1.01)$ & $0.74(0.55-1.01)$ \\
\hline 15 to 17 years & 52.4 & $1.02(0.81-1.29)$ & $0.80(0.59-1.07)$ & $0.79(0.59-1.07)$ & $0.81(0.60-1.08)$ & $0.80(0.60-1.08)$ \\
\hline 18 to 24 years & 60.4 & $1.42(1.12-1.80)^{* *}$ & $0.91(0.67-1.23)$ & $0.90(0.66-1.22)$ & $0.91(0.67-1.24)$ & $0.91(0.67-1.24)$ \\
\hline$\geq 25$ years & 56.3 & $1.19(0.82-1.74)$ & $0.89(0.53-1.48)$ & $0.89(0.53-1.50)$ & $0.86(0.52-1.44)$ & $0.86(0.52-1.44)$ \\
\hline \multicolumn{7}{|l|}{ Lifetime years of smoking } \\
\hline$\leq 1$ year & 67.1 & $2.54(2.13-3.03)^{* * *}$ & $\begin{array}{l}1.99 \\
(1.44-2.77)^{* * *}\end{array}$ & $\begin{array}{l}2.00 \\
(1.44-2.77)^{* * *}\end{array}$ & $\begin{array}{l}2.00 \\
(1.44-2.77)^{* * *}\end{array}$ & $\begin{array}{l}2.00 \\
(1.44-2.77)^{* * *}\end{array}$ \\
\hline $1-5$ years & 62.0 & $2.03(1.79-2.31)^{* * *}$ & $\begin{array}{l}1.62 \\
(1.23-2.13)^{* *}\end{array}$ & $\begin{array}{l}1.63 \\
(1.24-2.14)^{* *}\end{array}$ & $\begin{array}{l}1.63 \\
(1.24-2.14)^{* * *}\end{array}$ & $\begin{array}{l}1.63 \\
(1.24-2.14)^{* * *}\end{array}$ \\
\hline $6-10$ years & 52.7 & $1.38(1.21-1.58)^{* * *}$ & $1.27(0.99-1.63)$ & $1.28(0.99-1.64)$ & $1.27(0.99-1.63)$ & $1.27(0.99-1.62)$ \\
\hline $11-20$ years & 46.4 & $1.08(0.94-1.23)$ & $1.16(0.94-1.44)$ & $1.16(0.94-1.44)$ & $1.16(0.94-1.43)$ & $1.16(0.94-1.43)$ \\
\hline$\geq 20$ years & 44.6 & Ref. & Ref. & Ref. & Ref. & Ref. \\
\hline
\end{tabular}


Table 2 Factors associated with smokers' likelihood of reporting past 30-day abstinence from cigarette smoking at the 6-month assessment (Continued)

\begin{tabular}{|c|c|c|c|c|c|c|}
\hline & & \multirow[t]{2}{*}{ Unadjusted } & \multicolumn{2}{|l|}{ Model 1 adjusted } & \multicolumn{2}{|l|}{ Model 2 adjusted } \\
\hline & & & Step 1 & Step 2 & Step 1 & Step 2 \\
\hline Predictor variable & $\%$ P30A & Unadjusted OR (95\% Cl) & $\begin{array}{l}\mathrm{aOR} \\
(95 \% \mathrm{Cl})\end{array}$ & $\begin{array}{l}\mathrm{aOR} \\
(95 \% \mathrm{Cl})\end{array}$ & $\begin{array}{l}\mathrm{aOR} \\
(95 \% \mathrm{Cl})\end{array}$ & $\begin{array}{l}\mathrm{aOR} \\
(95 \% \mathrm{Cl})\end{array}$ \\
\hline \multicolumn{7}{|l|}{$\begin{array}{l}\text { Number of smoking days in } \\
30 \text { days prior to baseline }\end{array}$} \\
\hline 1-9 days & 67.3 & $2.48(2.17-2.83)^{* * *}$ & $2.37(1.97-2.85)^{* * *}$ & $2.38(1.98-2.87)^{* * *}$ & $2.36(1.96-2.83)^{* * *}$ & $2.36(1.96-2.83)^{* * *}$ \\
\hline 10-19 days & 66.5 & $2.39(2.09-2.74)^{* * *}$ & $2.15(1.79-2.57)^{* * * *}$ & $2.15(1.80-2.58)^{* * *}$ & $2.15(1.80-2.58)^{* * *}$ & $2.15(1.80-2.58)^{* * *}$ \\
\hline 20-29 days & 58.4 & $1.69(1.52-1.88)^{* * * *}$ & $1.49(1.30-1.71)^{* * *}$ & $1.50(1.30-1.72)^{* * *}$ & $1.49(1.30-1.71)^{* * *}$ & $1.49(1.30-1.72)^{* * *}$ \\
\hline 30 days & 45.3 & Ref. & Ref. & Ref. & Ref. & Ref. \\
\hline \multicolumn{7}{|l|}{ Cigarettes smoked per day at baseline } \\
\hline 1-9 cigarettes per day & 61.0 & Ref. & Ref. & Ref. & Ref. & Ref. \\
\hline 10-19 cigarettes per day & 48.4 & $0.60(0.55-0.66)^{* * *}$ & $0.87(0.76-0.99)^{*}$ & $0.87(0.77-1.00)^{*}$ & $0.87(0.77-1.00)^{*}$ & $0.87(0.77-1.00)^{*}$ \\
\hline$\geq 20$ cigarettes per day & 42.8 & $0.48(0.43-0.54)^{* * *}$ & $0.78(0.66-0.92)^{* * *}$ & $0.78(0.66-0.92)^{* *}$ & $0.79(0.67-0.93)^{* *}$ & $0.79(0.67-0.93)^{* *}$ \\
\hline \multicolumn{7}{|l|}{$\begin{array}{l}\text { Number of days of JUUL use in } \\
\text { past } 30 \text { days (at } 6 \text { months) }\end{array}$} \\
\hline $1-9$ days & 40.6 & $0.45(0.38-0.52)^{* * *}$ & $0.38(0.31-0.45)^{* * *}$ & $0.38(0.31-0.45)^{* * *}$ & $0.36(0.30-0.43)^{* * *}$ & $0.36(0.30-0.43)^{* * *}$ \\
\hline 10-19 days & 40.4 & $0.44(0.39-0.51)^{* * *}$ & $0.39(0.33-0.46)^{* * *}$ & $0.39(0.33-0.46)^{* * *}$ & $0.38(0.32-0.44)^{* * *}$ & $0.38(0.32-0.44)^{* * *}$ \\
\hline 20-29 days & 47.5 & $0.59(0.53-0.67)^{* * *}$ & $0.45(0.39-0.52)^{* * *}$ & $0.45(0.39-0.52)^{* * *}$ & $0.44(0.38-0.51)^{* * *}$ & $0.44(0.38-0.51)^{* * *}$ \\
\hline 30 days & 60.4 & Ref. & Ref. & Ref. & Ref. & Ref. \\
\hline \multicolumn{7}{|l|}{$\begin{array}{l}\text { Current use of an e-cigarette } \\
\text { other than JUUL }\end{array}$} \\
\hline Yes & 46.6 & $0.71(0.63-0.81)^{* * *}$ & $0.80(0.67-0.95)^{*}$ & $0.79(0.67-0.95)^{*}$ & $0.80(0.67-0.95)^{*}$ & $0.80(0.67-0.95)^{*}$ \\
\hline No & 55.0 & Ref. & Ref. & Ref. & Ref. & Ref. \\
\hline \multicolumn{7}{|l|}{ Place of first JUUL purchase } \\
\hline Retail store & 59.0 & $1.45(1.34-1.58)^{* * *}$ & $1.22(1.08-1.37)^{* *}$ & $1.24(0.89-1.74)$ & $1.23(1.10-1.38)^{* * *}$ & $1.35(0.93-1.95)$ \\
\hline JUUL website & 49.8 & Ref. & Ref. & Ref. & Ref. & Ref. \\
\hline \multicolumn{7}{|l|}{$\begin{array}{l}\text { Bought JUUL SK "to help me } \\
\text { quit smoking" }\end{array}$} \\
\hline Yes & 54.4 & $1.10(0.98-1.23)$ & $1.46(1.26-1.68)^{* * *}$ & $1.46(1.26-1.69)^{* * *}$ & $1.47(1.27-1.70)^{* * *}$ & $1.47(1.27-1.70)^{* * *}$ \\
\hline No & 52.1 & Ref. & Ref. & Ref. & Ref. & Ref. \\
\hline \multicolumn{7}{|l|}{$\begin{array}{l}\text { Primary JUULpod flavor used in } \\
\text { past } 30 \text { days (at } 6 \text { months) }\end{array}$} \\
\hline Virginia tobacco & 47.0 & Ref. & Ref. & Ref. & Ref. & Ref. \\
\hline Mint & 59.5 & $1.66(1.41-1.94)^{* * *}$ & $1.45(1.20-1.76)^{* * *}$ & $1.51(1.19-1.91)^{* *}$ & $\mathrm{NI}$ & $\mathrm{Nl}$ \\
\hline Mango & 58.7 & $1.60(1.37-1.87)^{* * *}$ & $1.39(1.15-1.67)^{* * *}$ & $1.44(1.15-1.82)^{* *}$ & $\mathrm{NI}$ & $\mathrm{NI}$ \\
\hline Crème & 45.2 & $0.93(0.73-1.18)$ & $0.96(0.73-1.27)$ & $1.05(0.74-1.49)$ & $\mathrm{NI}$ & $\mathrm{NI}$ \\
\hline Fruit & 48.7 & $1.07(0.81-1.41)$ & $1.30(0.94-1.81)$ & $1.34(0.89-2.04)$ & $\mathrm{NI}$ & $\mathrm{NI}$ \\
\hline Cucumber & 49.4 & $1.10(0.86-1.41)$ & $0.91(0.68-1.22)$ & $0.80(0.55-1.15)$ & $\mathrm{NI}$ & $\mathrm{Nl}$ \\
\hline Classic tobacco & 31.8 & $0.52(0.37-0.74)^{* * *}$ & $0.82(0.54-1.24)$ & $0.79(0.48-1.31)$ & $\mathrm{NI}$ & $\mathrm{NI}$ \\
\hline Menthol & 46.7 & $0.99(0.77-1.26)$ & $1.01(0.75-1.36)$ & $1.01(0.70-1.46)$ & $\mathrm{NI}$ & $\mathrm{NI}$ \\
\hline $\begin{array}{l}\text { Equal use of } 2+\text { flavors, } \\
\text { no primary }\end{array}$ & 50.6 & $1.16(0.98-1.36)$ & $1.06(0.87-1.29)$ & $0.99(0.77-1.28)$ & $\mathrm{Nl}$ & $\mathrm{NI}$ \\
\hline \multicolumn{7}{|l|}{$\begin{array}{l}\text { JUULpod flavors used in } \\
\text { the past } 30 \text { days (at } 6 \text { months) }\end{array}$} \\
\hline Only used JUUL tobacco flavors ${ }^{\Delta}$ & 43.1 & Ref. & $\mathrm{NI}$ & $\mathrm{NI}$ & Ref. & Ref. \\
\hline Only used JUUL characterizing flavors^ & 56.3 & $1.70(1.47-1.98)^{* * *}$ & $\mathrm{NI}$ & $\mathrm{NI}$ & $1.37(1.14-1.65)^{* *}$ & $1.41(1.13-1.75)^{* *}$ \\
\hline Used flavors from both tobacco and categories & 47.1 & $1.18(0.98-1.41)$ & $\mathrm{NI}$ & $\mathrm{NI}$ & $0.98(0.79-1.22)$ & $1.03(0.79-1.35)$ \\
\hline \multicolumn{7}{|l|}{$\begin{array}{l}\text { Interaction term: primary JUULpod flavor } \\
\text { used in past } 30 \text { days (at } 6 \text { months) } \times \\
\text { place of first JUUL purchase }\end{array}$} \\
\hline Virginia tobacco $\times$ retail & & & & Ref. & $\mathrm{NI}$ & $\mathrm{Nl}$ \\
\hline
\end{tabular}


Table 2 Factors associated with smokers' likelihood of reporting past 30-day abstinence from cigarette smoking at the 6-month assessment (Continued)

\begin{tabular}{|c|c|c|c|c|c|c|}
\hline & & \multirow{3}{*}{$\begin{array}{l}\text { Unadjusted } \\
\text { Unadjusted OR (95\% CI) }\end{array}$} & \multicolumn{2}{|c|}{ Model 1 adjusted } & \multicolumn{2}{|c|}{ Model 2 adjusted } \\
\hline & & & Step 1 & Step 2 & Step 1 & Step 2 \\
\hline Predictor variable & $\%$ P30A & & $\begin{array}{l}\mathrm{aOR} \\
(95 \% \mathrm{Cl})\end{array}$ & $\begin{array}{l}\mathrm{aOR} \\
(95 \% \mathrm{Cl})\end{array}$ & $\begin{array}{l}\mathrm{aOR} \\
(95 \% \mathrm{Cl})\end{array}$ & $\begin{array}{l}\mathrm{aOR} \\
(95 \% \mathrm{Cl})\end{array}$ \\
\hline Mint $\times$ retail & - & - & - & $0.92(0.62-1.37)$ & $\mathrm{NI}$ & $\mathrm{Nl}$ \\
\hline Mango $\times$ retail & - & - & - & $0.91(0.62-1.35)$ & $\mathrm{NI}$ & $\mathrm{NI}$ \\
\hline Crème $\times$ retail & - & - & - & $0.78(0.44-1.40)$ & $\mathrm{NI}$ & $\mathrm{NI}$ \\
\hline Fruit $\times$ retail & - & - & - & $0.93(0.48-1.81)$ & $\mathrm{NI}$ & $\mathrm{NI}$ \\
\hline Cucumber $\times$ retail & - & - & - & $1.42(0.77-2.62)$ & $\mathrm{NI}$ & $\mathrm{NI}$ \\
\hline Classic tobacco $\times$ retail & - & - & - & $1.12(0.45-2.76)$ & $\mathrm{NI}$ & $\mathrm{NI}$ \\
\hline Menthol $\times$ retail & - & - & - & $0.99(0.54-1.83)$ & $\mathrm{NI}$ & $\mathrm{NI}$ \\
\hline $\begin{array}{l}\text { Equal use of } 2+\text { flavors, no } \\
\text { primary } \times \text { retail }\end{array}$ & - & - & - & $1.13(0.75-1.70)$ & $\mathrm{NI}$ & $\mathrm{NI}$ \\
\hline \multicolumn{7}{|l|}{$\begin{array}{l}\text { Interaction term: JUULpod flavors used in } \\
\text { the past } 30 \text { days (at } 6 \text { months) } \times \text { place of } \\
\text { first JUUL purchase }\end{array}$} \\
\hline Only JUUL tobacco flavors $\times$ retail & - & - & $\mathrm{NI}$ & $\mathrm{NI}$ & - & Ref. \\
\hline Only JUUL characterizing flavors $\times$ retail & - & - & $\mathrm{NI}$ & $\mathrm{NI}$ & - & $0.92(0.62-1.35)$ \\
\hline Both flavor categories and tobacco $\times$ retail & - & - & $\mathrm{NI}$ & $\mathrm{NI}$ & - & $0.86(0.54-1.36)$ \\
\hline 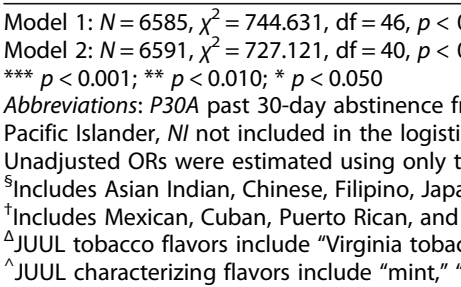 & $\begin{array}{l}\text { smoking a } \\
\text { gression m } \\
\text { levant va } \\
\text {, Korean, } \\
\text { er Hispan } \\
\text { and "class } \\
\text { go," "crèm }\end{array}$ & $\begin{array}{l}\text { the 6-month assessmer } \\
\text { odel } \\
\text { riable as the predictor va } \\
\text { Vietnamese, Guamanian, } \\
\text { ic" ethnicity } \\
\text { ic tobacco" } \\
\text { e," "fruit," "cucumber," ar }\end{array}$ & t, $a O R$ adju & s ratio, HS high s & $\mathrm{ol}, C P D \mathrm{ci}$ & moked per day, $P$ \\
\hline
\end{tabular}

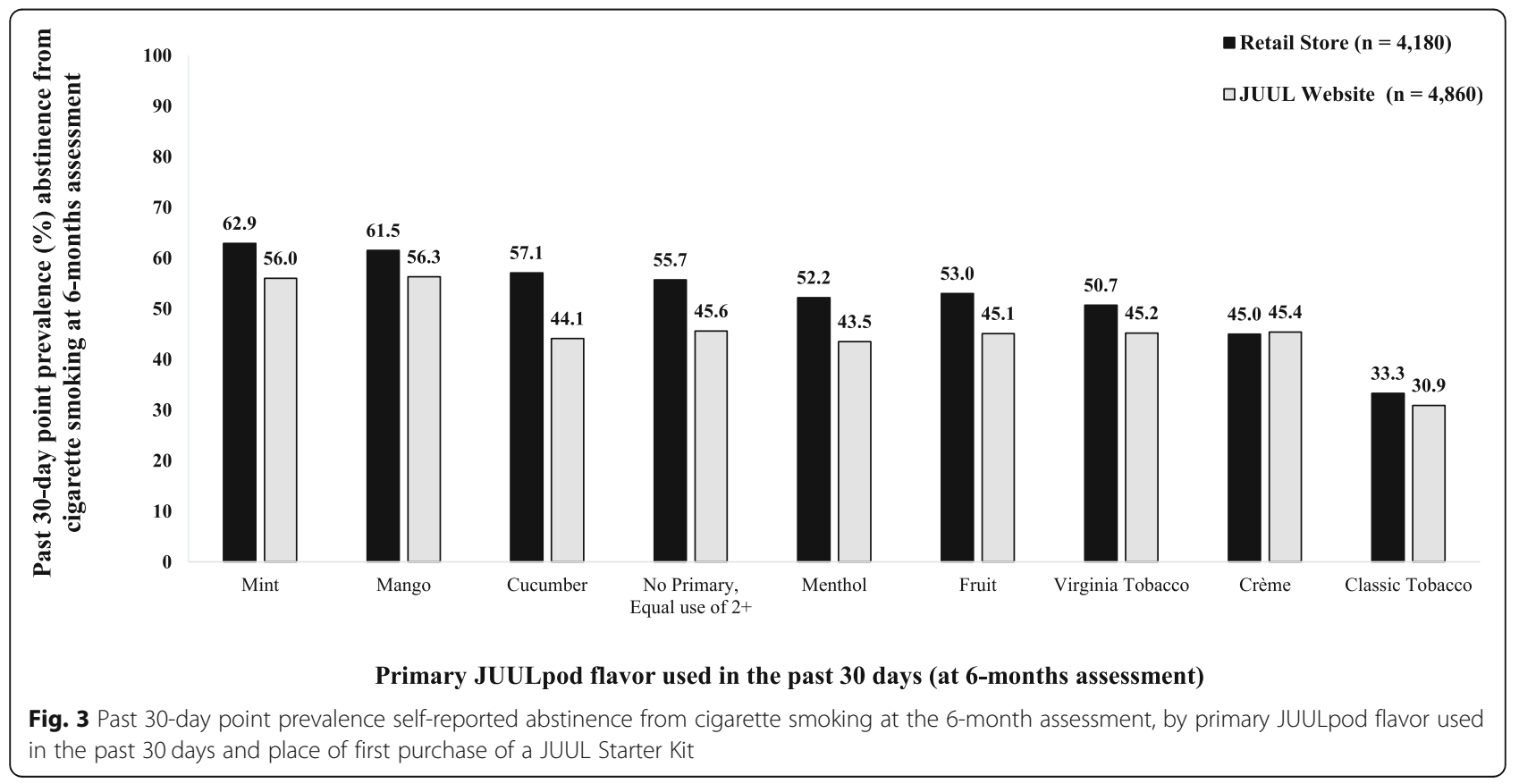


$25 \%$ less likely to have abstained from smoking in the 30 days prior to the 6 -month assessment $(\mathrm{aOR}=0.80$; $0.67,0.95)$.

Cigarette smoking-related factors Heaviness, frequency, and lifetime duration of cigarette smoking at the time of first purchase of a JUUL Starter Kit were all negatively associated with participants' odds of reporting past 30-day smoking abstinence at the 6-month assessment. Compared to those who had smoked cigarettes on all 30 of the 30 days prior to the baseline assessment, those who had smoked cigarettes on $20-29$ ( $\mathrm{aOR}=1.49$; $1.30,1.71), 10-19(\mathrm{aOR}=2.15 ; 1.79,2.57)$, and $1-9$ $(\mathrm{aOR}=2.37 ; 1.97,2.85)$ of the past 30 days were approximately 1.5 times, 2.2 times, and 2.4 times more likely, respectively, to have not smoked a cigarette in the 30 days prior to the 6-month assessment.

Compared to those who were smoking 1-9 cigarettes per smoking day in the 30 days prior to the baseline assessment, those who were smoking 10-19 cigarettes per day $(\mathrm{aOR}=0.87 ; 0.76,0.99)$ and 20 or more cigarettes per day $(\mathrm{aOR}=0.78 ; 0.66,0.92)$ were $15 \%$ and $28 \%$ less likely, respectively, to have not smoked a cigarette in the 30 days prior to the 6-month assessment. Compared to those reported having smoked cigarettes regularly for 20 or more years in their lifetime at the baseline assessment, those who had smoked cigarettes regularly for 0 12 months $(\mathrm{aOR}=1.99 ; 1.44,2.77)$ and $1-5$ years $(\mathrm{aOR}=$ $1.62 ; 1.23,2.13$ ) were $99 \%$ and $62 \%$ more likely, respectively, to have not smoked a cigarette in the 30 days prior to the 6-month assessment.

Demographic factors Compared to those who had not graduated high school, those with a GED were 55\% more likely to have abstained from smoking in the 30 days prior to the 6-month assessment $(\mathrm{aOR}=1.55 ; 1.03$, 2.34). Compared to those who lived in the West census region, those who lived in the Northeast $(\mathrm{aOR}=0.84$; $0.71,0.99)$ and Midwest $(\mathrm{aOR}=0.84 ; 0.71,0.99)$ census regions were $19 \%$ and $19 \%$ less likely, respectively, to have not smoked a cigarette in the 30 days prior to the 6-month assessment.

\section{Model 2}

All variables that emerged in model 1 as significant predictors of past 30-day smoking abstinence at the 6month assessment remained significant in model 2, with no non-significant predictors in model 1 becoming significant in model 2 . The added predictor variable-use of JUULpod flavor categories in the 30 days prior to the 6-month assessment-was significantly associated with participants' odds of reporting past 30-day abstinence from smoking at the 6-month assessment. Compared to those who had exclusively used JUULpods in tobacco flavors in the 30 days prior to the 6-month assessment, those who had exclusively used JUULpods in characterizing flavors were $37 \%$ more likely to have abstained from smoking in the 30 days prior to the 6 month assessment $(\mathrm{aOR}=1.37 ; 1.14,1.65)$. The interaction term entered at step 2 was non-significant, indicating the association between past 30-day use of JUULpod flavor categories and past 30-day smoking abstinence at the 6-month assessment was not moderated by the place at which participants purchased their first JUUL Starter Kit.

\section{Discussion}

This study prospectively assessed rates of self-reported past 30-day abstinence from cigarette smoking in a large cohort of US adult established current smokers up to 6 months after their first purchase of a JUUL vaporizer. Participants who were still using a JUUL vaporizer and participating in the study after 6 months were typically male, aged 21-34 years, non-Hispanic White, and college-educated, had initiated smoking before aged 18, had smoked cigarettes regularly for fewer than 10 years in their lifetime, and had been daily smokers of 1-9 cigarettes when they purchased their first JUUL Starter Kit. In a worst-case scenario in which non-respondents to survey assessments were assumed to have resumed smoking cigarettes, past 30-day point prevalence abstinence from cigarette smoking was found to have increased from $28.3 \%$ at 3 months to $31.6 \%$ at 6 months, with $20.3 \%$ of participants reporting consecutive past 30-day smoking abstinence outcomes at 3 and 6 months. Additionally, a higher rate of quitting smoking (11.3\%) than lapsing to smoking $(8.0 \%)$ was observed between the third and sixth months of using a JUUL vaporizer.

The impact of the switching from combustible cigarettes to JUUL use on the health of this cohort of adult smokers will depend on the health risks associated with using JUUL products relative to the risks associated with continuing to smoke cigarettes. Though the long-term health risks of e-cigarette use are unknown, and likely will not be well characterized for several years, the best available evidence suggests that, under typical conditions of use, the aerosol emitted by e-cigarettes typically contains fewer and lower concentrations of toxicants and carcinogens than are present in smoke from combustible tobacco cigarettes $[1,30,31]$. If switching completely from smoking cigarettes to using JUUL vaping products specifically is demonstrated to reduce adult smokers' risks for premature mortality and smoking-related disease to levels that are, at a minimum, significantly below the level of risk associated with continuing to smoke cigarettes, and ideally, statistically equivalent to the levels of risk associated with quitting all tobacco and nicotine 
use, then the observed rates of complete switching from cigarette smoking to use of a JUUL vaporizer would likely represent a substantial improvement in the health status of this cohort.

However, if the health risks of using a JUUL vaporizer are found to be similar to those associated with smoking cigarettes, the observed rates of complete switching and dual use of cigarettes and JUUL products would likely represent increased harm to the health of these adult smokers. Currently, there is insufficient evidence to conclude that switching completely from cigarettes to JUUL products may modify an adult smoker's risk of developing serious health problems relative to continuing to smoke tobacco. Empirical data that characterize the risk/ safety profile of JUUL vapor products relative to combustible cigarettes, other ENDS products, FDA-approved smoking cessation products, and medications, and to stopping use of all tobacco and nicotine products are therefore urgently needed to more accurately position these products on a continuum of health risk, and so inform the extent to which adult smokers who are unwilling or unable to stop consuming nicotine should be advised to switch from smoking conventional cigarettes to using JUUL vaping products.

Present findings give insight to the patterns of cigarette smoking prior to JUUL initiation and to the patterns of use of JUUL products that may facilitate and impede smokers' efforts to completely switch to using a JUUL vaporizer within 6 months. Consistent with findings from nationally representative surveys, smokers who reported using a JUUL vaporizer daily at the 6-month assessment were more than twice as likely to have not smoked any cigarettes in those 30 days compared to those who used a JUUL vaporizer less than daily. The use of JUULpods containing characterizing flavors was also found to be an important determinant of smokers' likelihood of having quit smoking at 6 months. Smokers who reported exclusively using JUULpods containing characterizing flavors-mint, mango, crème, fruit, classic menthol, and/or cucumber-in the 30 days prior to the 6-month assessment were around $38 \%$ more likely to have abstained from smoking in those 30 days compared to those who used only JUULpods containing tobacco flavors-Virginia tobacco and/or classic tobacco. Mint or mango was the most commonly used JUULpod flavors at 6 months, and smokers who reported mint and mango as their primary JUULpod flavor choice in the 30 days prior to 6 months were around $46 \%$ and $40 \%$ more likely to have quit smoking, respectively, compared to those who had primarily used Virginia tobacco-flavored JUULpods. For context, a previous regression analysis found past 30-day primary users of mint- and mango-flavored JUULpods were $37 \%$ and $26 \%$ more likely than primary users of Virginia tobacco-flavored JUULpods to be past 30-day abstinent from smoking at 3 months [29].. Present findings therefore suggest the associations between past 30-day primary use of mint- and mango-flavored JUULpods and past 30day smoking abstinence strengthened between the third and sixth months of JUUL use.

The debate about the ratio at which flavored ecigarettes contribute both to smoking cessation and to tobacco use initiation among youth and non-users at the population level has become increasingly polarized. The FDA has statutory authority over the regulation of flavored e-cigarettes, but any action the agency decides to take must, in the words of Former Commissioner, Dr. Scott Gottlieb, strike a careful public health balance between maintaining access to potentially less harmful sources of nicotine through e-cigarettes for adults who want to transition away from combustible cigarettes, while reducing youth appeal and access to ecigarettes. A recent editorial in the New England Journal of Medicine [32] suggested "the FDA should simply ban the sale of flavored nicotine products for use in ecigarettes. The public health problem that e-cigarettes can help solve - by helping people who are users of combustible tobacco products stop smoking by switching to vaping - is adequately addressed by liquids that are not flavored to appeal to adolescents." On this basis, the authors urged the FDA "to use its statutory powers in regulating nicotine delivery devices to take the bold step of removing these flavored products from the market."

The premise for the authors' arguing for a complete ban on flavored e-cigarettes is their contention that ecigarettes flavored to taste like tobacco should be sufficiently appealing and effective to assist adult smokers to transition away from smoking cigarettes. It should be stressed that the present findings neither support the argument that access to JUULpods containing nontobacco flavors is essential for adult smokers to completely substitute a JUUL vaporizer for conventional cigarettes, nor do they rule out the possibility that adult smokers would simply switch to using available tobacco-flavored e-cigarettes in the event that their preferred non-tobacco-flavored products were banned. However, the present finding of a significantly higher odds of quitting smoking associated with the use of non-tobacco-flavored JUULpods contradicts would suggest the opposite hypothesis is more likely to be true: restricting adult smokers' access to only JUULpods containing tobacco flavors may have the effect of diminishing adult smokers' openness to try using a JUUL vaporizer as an alternative to continuing to smoke cigarettes and may reduce the likelihood that adult smokers who do begin using a JUUL vaporizer will attempt to quit or cut down smoking and succeed in those attempts. 
Investigation of this potential negative effect has become more urgent since JUUL Labs Inc. announced, on 13 November 2018, the company would immediately stop selling its mango-, crème-, fruit-, and cucumber-flavored refill pods to the over 90,000 retail stores in the USA that currently sell JUUL's flavored refill pods, including convenience stores and specialty vape stores. This action was taken in response to concern expressed by the FDA about the role of nontobacco flavors in increasing the appeal of vaping to youth, JUUL Labs Inc. Given the current evidence of significantly higher smoking abstinence rates among users of JUULpods containing characterizing flavors and among those who purchased their first JUUL vaporizer in a retail store, the impact of this voluntary action on smoking cessation rates among users of the JUUL vaporizer should be closely assessed. The 6month data reported here, collection of which concluded on 3 January 2019, may serve as an important baseline for evaluating change in smoking abstinence and relapse rates among users of JUUL products during the period following the removal of flavored JUULpods from retail stores. The collection of data at 12 months will usefully address these questions.

If a statutory ban or voluntary suspension of flavored JUUL products from retail stores were to depress smoking cessation among adults, such actions could then only be justified from a public health perspective if the health benefits that are projected to be lost through a reduction in smoking cessation are outweighed by the health benefits that are projected to be gained from a reduced rate of youth initiation of e-cigarette and other tobacco use attributable to the banning of flavored e-cigarettes. Estimating the impact of JUUL vapor products on the health of the whole population therefore requires collection of data on the use of JUULpods in non-tobacco flavors by youth and non-smokers and the impact of use of these products on these individuals' use of other tobacco products that may carry more harm, such as conventional cigarettes, to give context to present data that show a significantly higher rate of smoking cessation at 6 months among adults who primarily or regularly use JUULpods in characterizing flavors.

The conclusions of this study are limited in several ways. Smoking abstinence at 3 and 6 months was selfreported, and biochemical verification of self-reported abstinence was not possible due to the large sample size and remote collection of data. Relatedly, it was not possible to estimate change in participants' overall nicotine consumption associated with their substitution of combustible cigarettes for JUULpods. Though participants were incentivized with $\$ 30$ to complete each survey, $41.5 \%$ of smokers were lost to follow-up at 6 months. Though the study invitation and informed consent procedure conveyed no expectation or requirement that smokers quit smoking in the next 6 months, some may have been unwilling to continue to respond to surveys if they felt embarrassed about not having quit smoking after 6 months. Others may have simply not wanted to continue to provide data after they had quit smoking. Recoding missing respondents as active smokers therefore represents the worst-case estimate of the effect of using JUUL products, but may not represent a realistic estimate. Abstinence rates reported for all enrolled participants and for only those who responded to surveys at 3 and 6 months should therefore be interpreted as lower and upper bound estimates of the effect of using JUUL products on smoking abstinence. Another possible reason for drop-out was that the survey web-link sent to participants by email at the 3 and 6 months was only active for a 10-day window. The researchers received many emails from participants who had not completed their survey before the web-link expired and asked to be sent a new web-link. These requests were rejected in order to maintain a strict measure of change in patterns of cigarette smoking and JUUL use at each assessment that was tied to the time of completion of the participant's baseline assessment.

Present findings are likely to be valid for adult smokers in the USA who purchase a JUUL Starter Kit of their own volition and use a JUUL vaporizer ad libitum. Findings are less likely to be generalizable to the US adult population of smokers or e-cigarette users, adult smokers who use other brands of e-cigarette, adult smokers who use a JUUL vaporizer for reasons other than to support an attempt to quit smoking, and adult smokers who are less motivated to use ecigarettes, such as those randomized to receive ecigarettes or other alternative nicotine products as part of a clinical trial. Several characteristics of the current study design should also caution readers against directly comparing quit rates observed in this study to those reported from randomized controlled trials of ecigarettes and other nicotine replacement products for smoking cessation. In this study, participants were adults who had purchased JUUL products naturalistically and were recruited opportunistically, observed remotely with no contact from the study investigators, and given no guidance or instruction as to how they should or should not use their JUUL vaporizer. Such naturalistic real-world conditions of product purchase and use are not typical of RCTs of nicotine replacement products. Directly comparing the quit rates observed in a cohort of naturalistic JUUL users against quit rates observed in a trial characterized by tightly controlled participant inclusion/exclusion criteria, conditions of participation, pre-specified and homogeneous regimens of product use, and frequent contact with clinical staff, is therefore ill-advised. 
Lastly, by including only those who were adult established current smokers at the time of their first purchase of a JUUL Starter Kit, this study additionally does not yield data on the proportion of all new JUUL purchasers who are adults (versus adolescents) or current smokers (versus former smokers and never smokers). In turn, this study yields no data about the rate of smoking initiation and smoking relapse among those who were not actively smoking or had never smoked a cigarette, respectively, when they purchased their first JUUL vaporizer. Estimating these rates is essential for modeling the impact of using JUUL vapor products on the health of the whole US population, the majority of whom are non-users of tobacco products.

\section{Conclusions}

This study provides evidence of the rate at which a cohort of adult smokers in the USA had completely quit smoking cigarettes 6 months after purchasing a JUUL vaporizer. Around one third of enrolled smokers and one half of smokers who responded to a 6-month follow-up reported being past 30-day abstinent from cigarette smoking after using a JUUL vaporizer for 6 months. The study also identified patterns of use of JUUL products and conventional cigarettes that increased and decreased smokers' likelihood of having quit smoking at 6 months. More frequent use of a JUUL vaporizer and primary use of JUULpods in characterizing flavors, particularly mint and mango, appeared to be important to smokers' chances of quitting. The impact of suspending retail sales of flavored JUULpods on adult smokers' likelihood of quitting should be closely assessed.

\section{Acknowledgements}

We would like to thank all of the individuals who gave their time to participate in this study.

\section{Authors' contributions}

$C R$ and NM conceived of the study. CR developed the survey instrument. CR and $\mathrm{FH}$ conducted the data analyses. $\mathrm{CR}, \mathrm{FH}$, and NM wrote the manuscript. All authors read and approved the final manuscript.

\section{Funding}

Funding for this study was provided by JUUL Labs Inc. JUUL Labs Inc. had no input to or control over the study design, contents of the survey instrument, sample recruitment, data analysis, interpretation, or reporting of findings. The authors alone are responsible for the contents, production, and decision to report this study.

\section{Availability of data and materials}

The de-identified datasets analyzed in the current study may be made available to researchers who submit a proposal that is approved by the principal investigator.

\section{Ethics approval and consent to participate}

Using the Department of Health and Human Services regulations found at 45 CFR 46.101(b)(2), Advarra Institutional Review Board (IRB) determined the component of this study involving the collection of data from individuals who purchased a JUUL Starter Kit in a retail store to be exempt from IRB oversight (Exempt Determination received 5 April 2018; Protocol Number
00024906). Data are also reported by 7633 age-verified adults who opted in to JUUL Labs Inc.'s internal market research surveys when purchasing JUUL products online. Informed consent to participate was obtained from all participants. The Informed Consent Form used in the current study is available from the corresponding author on reasonable request.

\section{Consent for publication}

Not applicable

\section{Competing interests}

In the past 12 months, the employer of CR and NM, the Centre for Substance Use Research, has received funding from JUUL Labs Inc. to conduct research on the impact of JUUL vapor products on tobacco use behaviors, perceptions, and intentions among adults and adolescents in the USA. In the past 3 years, the Centre for Substance Use Research has also received funding from several other e-cigarette manufacturers, including Fontem Ventures, Nicoventures, and Philip Morris International, to conduct research on tobacco harm reduction, specifically, on factors that encourage and discourage smokers from trialing and completely switching to using e-cigarettes.

Received: 26 June 2019 Accepted: 23 September 2019

Published online: 07 November 2019

\section{References}

1. Royal College of Physicians. Nicotine without smoke: tobacco harm reduction. London: RCP; 2016.

2. U.S. Public Health Service, Office of the Surgeon General, National Center for Chronic Disease Prevention and Health Promotion, Office on Smoking and Health. The health consequences of smoking -50 years of progress: a report of the Surgeon General. Atlanta, GA: DHHS, CDC, National Center for Chronic Disease Prevention and Health Promotion, Office on Smoking and Health; 2014.

3. Rostron BL, Chang CM, Pechacek TF. Estimation of cigarette smokingattributable morbidity in the United States. JAMA Intern Med. 2014;174(12): 1922-8.

4. Fiore MC, Jaén CR, Baker TB, et al. Treating tobacco use and dependence: 2008 update. In: Clinical practice guideline. Rockville: U.S. Department of Health and Human Services. Public Health Service; 2008.

5. Royal College of Physicians. Harm reduction in nicotine addiction: helping people who can't quit. In: A report by the Tobacco Advisory Group of the Royal College of Physicians. London: RCP; 2007.

6. Eriksen M, Mackay J, Ross H. The tobacco atlas. In: American Cancer Society and World Lung Foundation. 4th ed; 2012.

7. Babb S, Malarcher A, Schauer G, Asman K, Jamal A. Quitting smoking among adults - United States, 2000-2015. MMWR Morb Mortal Wkly Rep. 2017;65:1457-64.

8. Chaiton M, Diemert L, Cohen JE, Bondy SJ, Selby P, Philipneri A, et al. Estimating the number of quit attempts it takes to quit smoking successfully in a longitudinal cohort of smokers. BMJ Open. 2016;6:e011045.

9. Caraballo RS, Shafer PR, Patel D, Davis KC, MCAfee TA. Quit methods used by US adult cigarette smokers, 2014-2016. Prev Chronic Dis. 2017;14:160600.

10. Zhu SH, Zhuang YL, Wong S, Cummins SE, Tedeschi GJ. E-cigarette use and associated changes in population smoking cessation: evidence from US current population surveys. BMJ. 2017;358:j3262.

11. Brown J, Beard E, Kotz D, Michie S, West R. Real-world effectiveness of ecigarettes when used to aid smoking cessation: a cross-sectional population study. Addiction. 2014;109:1531-40.

12. Beard E, West R, Michie S, Brown J. Association between electronic cigarette use and changes in quit attempts, success of quit attempts, use of smoking cessation pharmacotherapy, and use of stop smoking services in England: time series analysis of population trends. BMJ. 2016;354:14645.

13. West $R$, Shahab $L$, Brown J. Estimating the population impact of e-cigarettes on smoking cessation in England. Addiction. 2016;111:1118-9.

14. Jackson S, Kotz D, West R, Brown J. Moderators of real-world effectiveness of smoking cessation aids: a population study. Addiction. 2019. https://doi. org/10.1111/add.14656.

15. Levy DT, Yuan Z, Luo Y, Abrams DB. The relationship of e-cigarette use to cigarette quit attempts and cessation: insights from a large, nationally representative U.S. survey. Nicotine Tob Res. 2018;20(8):931-9. 
16. Giovenco DP, Delnevo CD. Prevalence of population smoking cessation by electronic cigarette use status in a national sample of recent smokers. Addict Behav. 2018;76:129-34.

17. Coleman B, Rostron B, Johnson SE, Persoskie A, Pearson J, Stanton C, et al. Transitions in electronic cigarette use among adults in the Population Assessment of Tobacco and Health (PATH) study, waves 1 and 2 (20132015). Tob Control. 1999;28(1):50-9.

18. Berry KM, Reynolds LM, Collins JM, Siegel MB, Fetterman JL, Hamburg NM, et al. E-cigarette initiation and associated changes in smoking cessation and reduction: the Population Assessment of Tobacco and Health Study, 20132015. Tob Control. 2019;28(1):42-9.

19. Hartmann-Boyce J, McRobbie H, Bullen C, Begh R, Stead LF, Hajek P. Electronic cigarettes for smoking cessation. Cochrane Database Syst Rev. 2016;9:CD010216. https://doi.org/10.1002/14651858.CD010216.pub3.

20. Hajek P, Phillips-Waller A, Przulj D, Pesola F, Myers Smith K, Bisal N, et al. A randomized trial of E-cigarettes versus nicotine-replacement therapy. $\mathrm{N}$ Engl J Med. 2019;380(7):629-37.

21. Pasquereau A, Guignard R, Andler R, Nguyen-Thanh V. Electronic cigarettes, quit attempts and smoking cessation: a 6-month follow-up. Addiction. 2017: 112(9):1620-8

22. Brose LS, Hitchman SC, Brown J, West R, McNeill A. Is the use of electronic cigarettes while smoking associated with smoking cessation attempts, cessation and reduced cigarette consumption? A survey with a 1-year follow-up. Addiction. 2015;110(7):1160-8.

23. Benmarhnia T, Pierce JP, Leas E, et al. Can E-cigarettes and pharmaceutical aids increase smoking cessation and reduce cigarette consumption? Findings from a nationally representative cohort of American smokers. Am J Epidemiol. 2018;187(11):2397-404.

24. Coleman B, Rostron B, Johnson SE, et al. Transitions in electronic cigarette use among adults in the Population Assessment of Tobacco and Health (PATH) Study, Waves 1 and 2 (2013-2015). Tobacco Control. 2019;28:50-59.

25. Kalkhoran S, Chang Y, Rigotti NA. Electronic cigarette use and cigarette abstinence over two years among U.S. smokers in the Population Assessment of Tobacco and Health study. 2019. https://doi.org/10.1093/ntr/ ntz114 (1469-994X (Electronic)). LID - ntz114 [pii] LID.

26. Verplaetse TL, Moore KE, Pittman BP, Roberts W, Oberleitner LM, Peltier MR, et al. Intersection of e-cigarette use and gender on transitions in cigarette smoking status: findings across waves 1 and 2 of the Population Assessment of Tobacco and Health (PATH) study. Nicotine Tob Res. 2018;19. https://doi.org/10.1093/ntr/nty187.

27. Pecachek TF, Nayak P, Gregory KR, Weaver SR, Eriksen MP. The potential that electronic nicotine delivery systems can be a disruptive technology: results from a national survey. Nicotine Tob Res. 2016;18(10):1989-97.

28. Herzog B, Kanada P. Neilsen: tobacco all channel data thru 8/11 - Cig Vol Decelerates: Wells Fargo Securities, LLC; 2018. https://athra.org.au/wpcontent/uploads/2018/09/Wells-Fargo-Nielsen-Tobacco-All-Channel-ReportPeriod-Ending-8.11.18.pdf. Accessed 15 Feb, 2019

29. Russell C, Haseen F, McKeganey N. Factors associated with past 30-day abstinence from cigarette smoking in a non-probabilistic sample of 15,456 adult established current smokers in the United States who used JUUL vapor products for three months. Harm Reduct J. 2019;16(1):22.

30. National Academies of Sciences, Engineering, and Medicine. Public health consequences of e-cigarettes. Washington: The National Academies Press; 2018. https://doi.org/10.17226/24952.

31. McNeill A, Brose LS, Calder R, Bauld L, Robson D. Evidence review of ecigarettes and heated tobacco products 2018. In: A report commissioned by Public Health England. London: Public Health England; 2018.

32. Drazen JM, Morrisey S, Campion EW. Editorial: the dangerous flavors of ecigarettes. N Engl J Med. 2019;380(7):679-80.

\section{Publisher's Note}

Springer Nature remains neutral with regard to jurisdictional claims in published maps and institutional affiliations.

Ready to submit your research? Choose BMC and benefit from:

- fast, convenient online submission

- thorough peer review by experienced researchers in your field

- rapid publication on acceptance

- support for research data, including large and complex data types

- gold Open Access which fosters wider collaboration and increased citations

- maximum visibility for your research: over $100 \mathrm{M}$ website views per year

At BMC, research is always in progress.

Learn more biomedcentral.com/submissions 